\title{
Influence of some physico-chemical factors on properties of electrodes that decompose water catalytically
}

\author{
V.E. Primachenko, O.A. Serba, V.A. Chernobai, E.F. Venger \\ V. Lashkaryov Institute of Semiconductor Physics, NAS of Ukraine \\ 41, prosect Nauky,03028 Kyiv, Ukraine, e-mail: pve18@isp.kiev.ua
}

\begin{abstract}
We have investigated the current creation accompanied by the water decomposition $\mathrm{H}_{2} \mathrm{O} \rightarrow \mathrm{OH}+\mathrm{H}$ caused by various catalytically active electrodes with different electrochemical potentials, both without external electric voltage on these electrodes and with the applied voltage $V_{0}= \pm 9.7 \mathrm{~V}$. It is found that the current value and its time dependence are essentially influenced by such factors as thermal and natural (in ambient atmosphere) oxidation of electrodes (made of $\mathrm{Al}, \mathrm{Si}, \mathrm{Yb}, \mathrm{Ni}, \mathrm{Ti}, \mathrm{Cr}_{3} \mathrm{Si}$, and $\mathrm{Ni}_{3} \mathrm{Si}$ ), changing their relief (texturing, polishing), and the electrolytic deposition of palladium as an impurity on the surface $\left(\mathrm{Ti}, \mathrm{Cr}_{3} \mathrm{Si}\right)$. Changes in the current caused by the above factors are realized as a consequence of changes in both the electron work function inherent to these electrodes and their catalytical activity concerning the water decomposition both in the absence and the presence of the external voltage $V_{0}$.
\end{abstract}

Keywords: catalytically active electrodes, oxidation, water decomposition.

Manuscript received 20.10.06; accepted for publication 24.04.07; published online 19.10.07.

\section{Introduction}

One of the actual up-to-date problems is the power production with minimum injury to the ecology of ambient medium and minimum economic expenses. An example of solving this problem is the use of the difference of electrochemical potentials that is set by the nature in different substances or created, or changed in them, including the synthesis of new substances.

In our previous works [1-3], we studied the phenomenon of electric current creation accompanied with water decomposition $\mathrm{H}_{2} \mathrm{O} \rightarrow \mathrm{OH}+\mathrm{H}$ when dipping two electrodes with different electrochemical potentials into it, these electrodes (at least one of them) being a catalyst of the decomposition of water molecules.

As shown in these works [1-3], the catalytic decomposition of water is mainly realized due to the presence of physico-chemical inhomogeneities on the micro(nano) scale on the electrode surface and to strong electric fields existing there. In particular, we studied the influence of thermal oxidation of catalytically active Sibased electrodes on current magnitudes and time dependences inherent to these electrodes and counterelectrodes made of $\mathrm{Al}, \mathrm{Yb}, \mathrm{Pt}$ [3].

This work is devoted to the influence of electrodes made of $\mathrm{Al}, \mathrm{Yb}, \mathrm{Ni}, \mathrm{Ti}$, and $\mathrm{Cr}_{3} \mathrm{Si}$ on water decomposition. In addition, a considerable attention was paid to studying such factors as a change of the electrode relief (texturing, grinding, and polishing) and the electrochemical deposition of $\mathrm{Pd}$ on $\mathrm{Ti}, \mathrm{Cr}_{3} \mathrm{Si}$ electrodes.

\section{Experimental}

The method of our experiments was described in works [1-3] in detail. When dipping two different electrodes into distilled water simultaneously, there arises the difference of potentials $\Delta V_{k}$ between them, which, as a rule, is less than the difference between the electron work functions for these electrodes $\Delta \varphi$ (this difference $\Delta \varphi$ is equal to the difference between the electrochemical potentials of electrodes). After making the external electric circuit to be closed (the time $t=0$ ), we measured time dependences for the current, $J(t)$.

Since the area of electrodes $S$ and the distance between them $L$ for various electrode pairs are different, we compare the efficient conductivities $\sigma=J(t)\left(L / \Delta V_{k} S\right)$ $=A J(t)$ of the electrochemical systems, where $A=$ $=L /\left(\Delta V_{k} S\right) \mathrm{V}^{-1} \mathrm{~cm}^{-1}$. When the electric circuit was supplied with the additional external voltage $V_{0}= \pm 9.7 \mathrm{~V}$, we used the value $\left(\Delta V_{k} \pm V_{0}\right)$ instead of the value $\Delta V_{k}$.

Thermal oxidation of electrodes was realized at $T=$ $=450{ }^{\circ} \mathrm{C}$ for $4 \mathrm{~h}$ in dry $\mathrm{O}_{2}$, while natural oxidation took place under ambient atmospheric conditions and by applying these electrodes as anodes. The relief of electrodes was changed using emery-paper (for grinding), diamond paste on felt (for polishing), as well as using anisotropic chemical etching (texturing).

Before measuring the $\sigma=A J(t)$ dependence, we determined the electron work function inherent to the electrodes in use. To this end, we used a standard reference electrode made of $\operatorname{Pt}(\varphi=5.32 \mathrm{eV})$ [4], as $\mathrm{Pt}$ is 
the most chemically stable electrode in our investigations. The values of $\varphi$ for various electrodes were determined via calculations made after measuring the current between $\mathrm{Pt}$ and the investigated electrode in the forward and backward directions [1-3] and are presented in the table.

\section{Experimental results and discussion}

In our investigations, the electrode made of $\mathrm{Yb}$ that possesses a relatively low electron work function was mostly used as anode [1-3]. It is known (see, in particular, [1]) that, when $\mathrm{Yb}$ is oxidized, the values of $A J(t)$ are increased to some extent despite the growth of $\varphi$. Therefore, we studied first the changes of $\varphi$ and $A J(t)$ which accompany the changes of an $\mathrm{Yb}$ surface state. Fig. 1 shows the obtained dependences $A J(t)$ at $V_{0}=0$ for three states of the $\mathrm{Yb}$ surface: (i) naturally oxidized (initial) (curve 1); (ii) polished (curve 2); (iii) oxidized for three months when it is operating as anode (curve 3) after polishing.

As seen from Fig. 1, the dependences $A J(t)$ noticeably differ from each other only within the first 20 min after bridging the $\mathrm{Yb}$ and $\mathrm{Pt}$ electrodes. This is related both to different $\varphi$ values (and $\Delta V_{k}$, respectively) and the dependence of the catalytic activity of the $\mathrm{Yb}$ electrode on the degree of oxidation. As seen from the table, the values of $\varphi$ were as follows: $3.65,3.04$, and $3.67 \mathrm{eV}$, while $\Delta V_{k}$ were equal to $0.86,1.37$, and $0.85 \mathrm{~V}$.

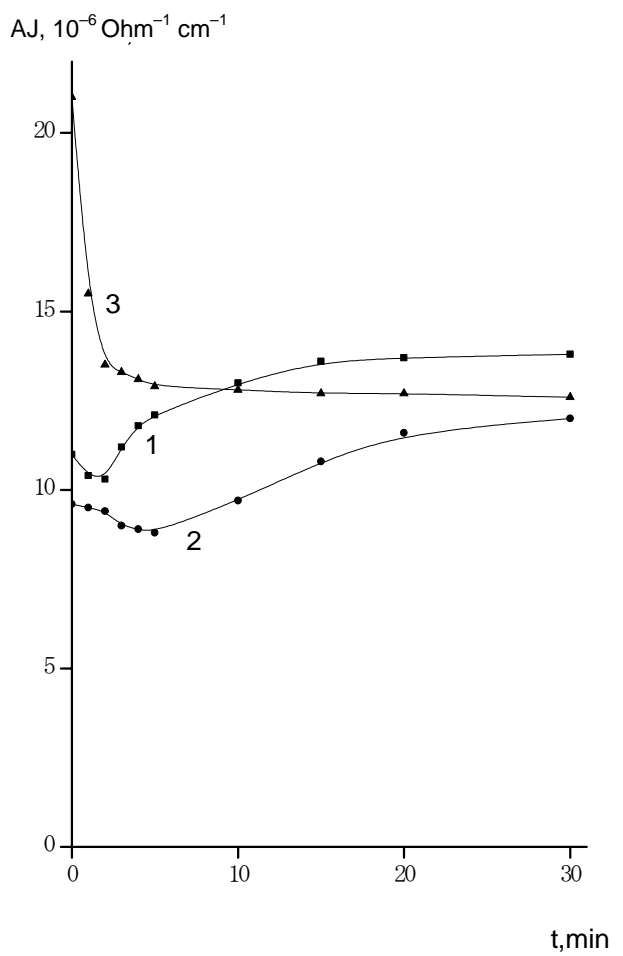

Fig. 1. Time dependences of the efficient conductivity $A J(t)$ when water is decomposed using the pair of electrodes $\mathrm{Yb}-\mathrm{Pt}$. The $\mathrm{Yb}$ electrode is: 1 - naturally oxidized; 2 - as polished; 3 oxidized after polishing and operation for 3 months.
Table. The electron work functions $\varphi$ for electrodes in various physico-chemical states.

\begin{tabular}{|c|c|c|}
\hline Electrode & $\begin{array}{c}\text { Electrode } \\
\text { symbol }\end{array}$ & $\varphi, \mathrm{eV}$ \\
\hline Aluminum as grinded & $\mathrm{Al}_{\mathrm{CB}}^{\mathrm{Gr}}$ & 4.12 \\
\hline Aluminum grinded and aged & $\mathrm{Al}_{\mathrm{AG}}^{\mathrm{Gr}}$ & 4.3 \\
\hline Aluminum plain and aged & $\mathrm{Al}^{\mathrm{P}}{ }_{\mathrm{AG}}$ & 4.57 \\
\hline $\begin{array}{l}\text { Aluminum } \mathrm{Al}^{\mathrm{P}}{ }_{\mathrm{AG}} \text { after thermal } \\
\text { oxidation }\end{array}$ & $\mathrm{Al}^{\mathrm{P}}{ }_{\mathrm{TO}}$ & 5.11 \\
\hline Aluminum textured and aged & $\mathrm{Al}_{\mathrm{AG}}^{\mathrm{T}}$ & 4.58 \\
\hline $\begin{array}{l}\text { Aluminum } \mathrm{Al}^{\mathrm{T}}{ }_{\mathrm{AG}} \text { after thermal } \\
\text { oxidation }\end{array}$ & $\mathrm{Al}^{\mathrm{T}}{ }_{\mathrm{AG}}$ & 5.12 \\
\hline Nickel (plane) & $\mathrm{Ni}$ & 4.82 \\
\hline Nickel thermally oxidized & $\mathrm{Ni}_{\mathrm{TO}}$ & 4.97 \\
\hline Chromium silicide & $\mathrm{Cr}_{3} \mathrm{Si}$ & 4.43 \\
\hline $\begin{array}{l}\text { Chromium silicide after thermal } \\
\text { oxidation }\end{array}$ & $\mathrm{Cr}_{3} \mathrm{Si}_{\mathrm{TO}}$ & 5.44 \\
\hline $\begin{array}{l}\text { Chromium silicide after Pd doping } \\
\left(1.5 \cdot 10^{16} \mathrm{~cm}^{-2}\right)\end{array}$ & $\begin{array}{l}\mathrm{Cr}_{3} \mathrm{Si} \\
\left\langle\mathrm{Pd}_{1}\right\rangle\end{array}$ & 4.53 \\
\hline $\begin{array}{l}\text { Chromium silicide after Pd doping } \\
\left(1 \cdot 10^{18} \mathrm{~cm}^{-2}\right)\end{array}$ & $\begin{array}{l}\mathrm{Cr}_{3} \mathrm{Si} \\
\left\langle\mathrm{Pd}_{5}\right\rangle \\
\end{array}$ & 6.24 \\
\hline Titanium as grinded & $\mathrm{Ti}_{\mathrm{CB}}^{\mathrm{Gr}}$ & 4.38 \\
\hline Titanium grinded and aged & $\mathrm{Ti}^{\mathrm{Gr}}{ }_{\mathrm{AG}}$ & 5.15 \\
\hline Titanium doped with $\mathrm{Pd}\left(2 \cdot 10^{16} \mathrm{~cm}^{-2}\right)$ & $\mathrm{Ti}\left\langle\mathrm{Pd}_{1}\right\rangle$ & 5.17 \\
\hline Titanium doped with $\mathrm{Pd}\left(1 \cdot 10^{18} \mathrm{~cm}^{-2}\right)$ & $\mathrm{Ti}\left\langle\mathrm{Pd}_{4}\right\rangle$ & 5.30 \\
\hline Titanium $\mathrm{TI}\left\langle\mathrm{Pd}_{4}\right\rangle$ thermally oxidized & $\mathrm{Ti}\left\langle\mathrm{Pd}_{4}\right\rangle_{\mathrm{TO}}$ & 5.42 \\
\hline Silicon textured and aged & $\mathrm{Si}^{\mathrm{T}}{ }_{\mathrm{AG}}$ & 4.85 \\
\hline Silicon $\mathrm{Si}^{\mathrm{T}}{ }_{\mathrm{AG}}$ after treatment in $\mathrm{HF}$ & $\mathrm{Si}_{\mathrm{HF}}^{\mathrm{T}}$ & 4.76 \\
\hline Ytterbium aged & $\mathrm{Yb}_{\mathrm{AG}}$ & 3.65 \\
\hline Ytterbium polished & $\mathrm{Yb}^{\mathrm{P}}$ & 3.04 \\
\hline $\begin{array}{l}\text { Ytterbium } \mathrm{Yb}^{\mathrm{P}} \text { after 1-month operation } \\
\text { as anode (oxidized) }\end{array}$ & $\mathrm{Yb}^{\mathrm{OX}}$ & 3.67 \\
\hline Nickel silicide & $\mathrm{Ni}_{3} \mathrm{Si}$ & 4.85 \\
\hline $\mathrm{Ni}_{3} \mathrm{Si}$ after thermal oxidation & $\mathrm{Ni}_{3} \mathrm{Si}_{\mathrm{TO}}$ & 4.88 \\
\hline
\end{tabular}

Considering the obtained data, it seems reasonable to make the following conclusions: (i) when measuring the $A J(t)$ dependences $20 \mathrm{~min}$ after the circuit closing, the values of $A J(t)$ are practically the same, i.e., the oxidizing degree of the $\mathrm{Yb}$ electrode does not influence its stable functioning; (ii) catalytic activity of the $\mathrm{Yb}$ electrode at $t<0$ and for the first minutes of the current transfer increases with its oxidation degree. It is not surprising, because not only the transition metals with their internal unfilled electron shells but also their oxides are catalytically active in reduction reactions (it is this reaction that provides water decomposition).

It is seen from the table that oxidation of all the electrodes in air and in the course of exploitation causes the growth of $\varphi$ which is more pronounced after thermal oxidation of electrodes. In most cases, thermal oxidation 


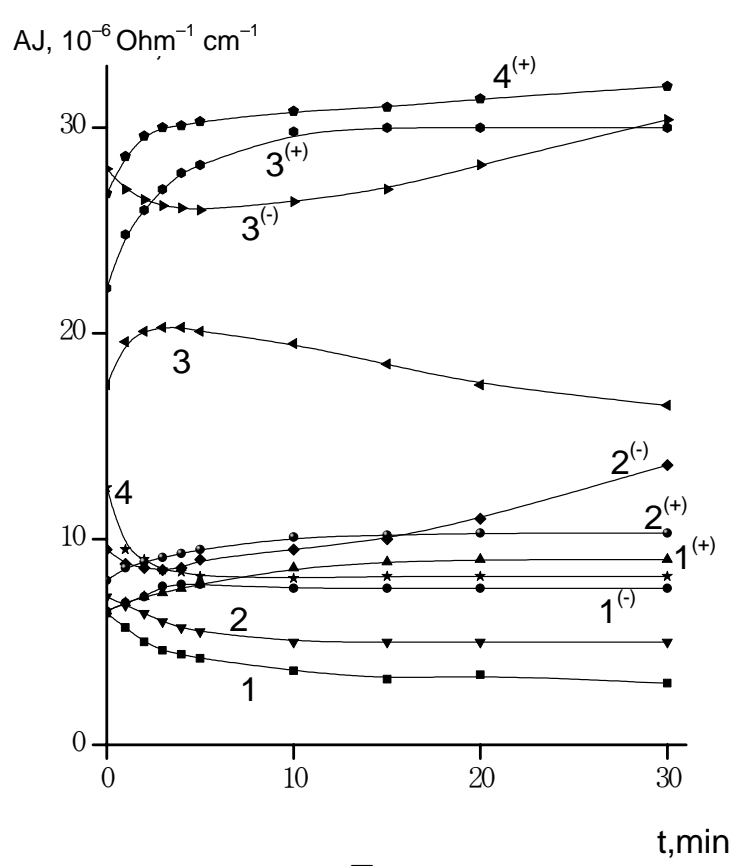

Fig. 2. $A J(t)$ dependences for the electrode pairs $\mathrm{Al}^{\mathrm{T}}{ }_{\mathrm{TO}}-\mathrm{Yb}(1$, $\left.1^{(+)}, 1^{(-)}\right), \mathrm{Ni}_{\mathrm{TO}} \mathrm{Yb}\left(2,2^{(+)}, 2^{(-)}\right), \mathrm{Cr}_{3} \mathrm{Si}_{\mathrm{TO}^{-}} \mathrm{Yb}\left(3,3^{(+)}, 3^{(-)}\right)$, $\mathrm{Ti}\left\langle\mathrm{Pd}_{4}\right\rangle_{\mathrm{TO}}-\mathrm{Yb}\left(4,4^{(+)}\right)$. The curves $1,2,3$ and 4 were obtained at $V_{0}=0$, curves marked with signs (+) and (-) at $V_{0}= \pm 9.7 \mathrm{~V}$ on the $\mathrm{Yb}$ electrode, respectively.

induces also the growth of $A J(t)$. Fig. 2 shows these dependences for thermally oxidized electrodes $\mathrm{Al}^{\mathrm{T}}{ }_{\mathrm{TO}}$, $\mathrm{Ni}_{\mathrm{TO}}, \mathrm{Gr}_{3} \mathrm{Si}_{\mathrm{TO}}$, and $\mathrm{Ti}\left\langle\mathrm{Pd}_{4}\right\rangle_{\mathrm{TO}}$ coupled with the aged $\mathrm{Yb}$ electrode. The superscripts (+) and $(-)$ indicate the $A J(t)$ dependences when the voltages $V_{0}= \pm 9.7 \mathrm{~V}$ are applied, respectively, to the $\mathrm{Yb}$ electrode.

Curves 1-4 were obtained at $V_{0}=0$. Comparing the dependences in Fig. 2 with the respective ones obtained before thermal oxidation of electrodes (in work [2] and in this one), we can draw conclusion that thermal oxidation increases the $A J(t)$ values (excluding the dependence for $\mathrm{Ti}\left\langle\mathrm{Pd}_{4}\right\rangle_{\mathrm{TO}}$ ) and often changes the character of their time dependences. It is indicative of the changes in the processes of catalytic decomposition of water molecules on electrodes as a consequence of the creation of oxide films thermally grown on them.

A natural oxide film can provide the current creation along with water decomposition in some other way as compared to the thermally grown one. It was shown in [3] that a thermally grown film on $\mathrm{Si}$ increases the electron work function up to $10 \ldots 11 \mathrm{eV}$ and essentially changes the $A J(t)$ dependences when the $\mathrm{Si}$ electrode is coupled with $\mathrm{Al}, \mathrm{Yb}$, and $\mathrm{Pt}$ counterelectrodes.

As seen from the table, the HF etching of the natural oxide film on a textured silicon electrode $\mathrm{Si}^{\mathrm{T}}{ }_{\mathrm{AG}}$ aged for 10 years [6] changes $\varphi$ only a little (from 4.85 down to $4.76 \mathrm{eV})$, while the character of the $A J(t)$ dependences is changed noticeably (Fig. 3a and b), but in another manner as compared to that in [3].
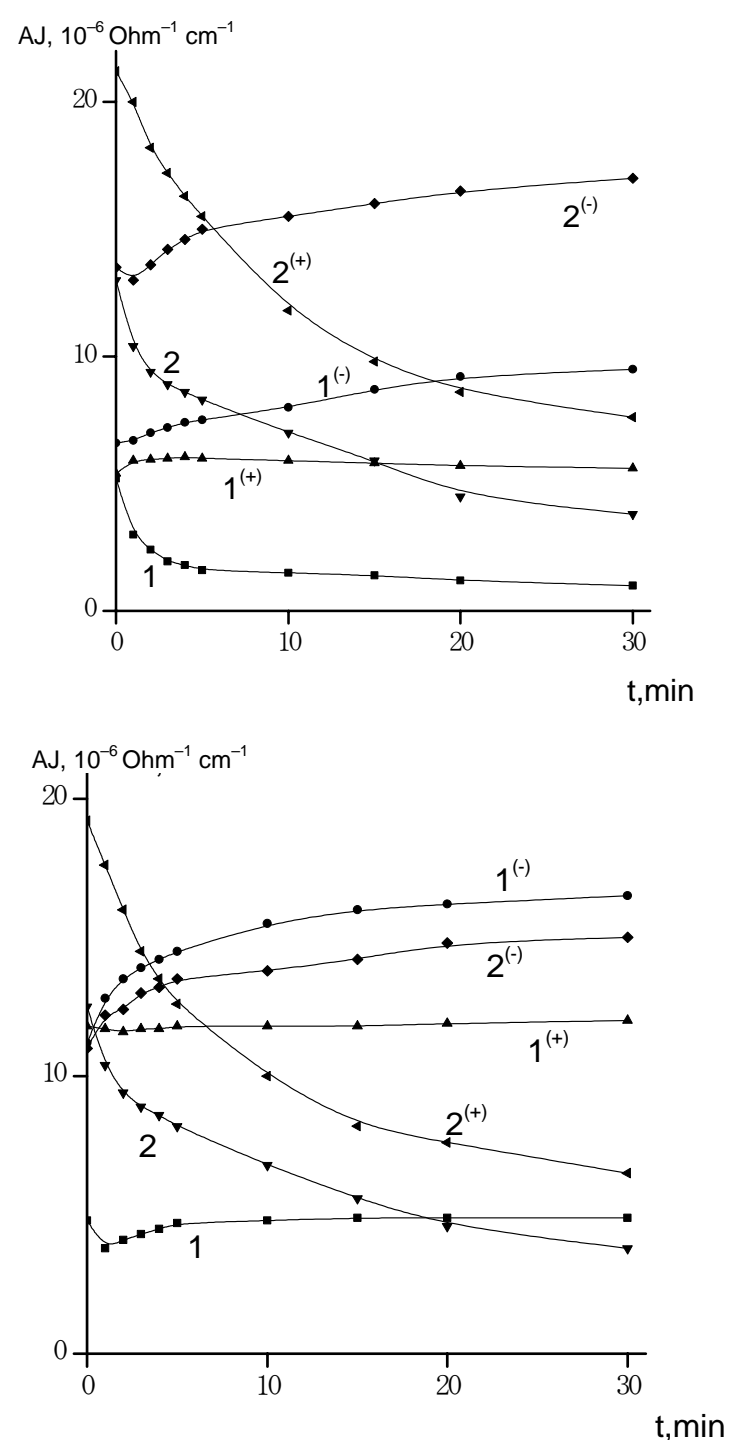

Fig. 3. $A J(t)$ dependences for the electrode pairs $\mathrm{Si}^{\mathrm{T}}-\mathrm{Pt}$ (a) and $\mathrm{Si}^{\mathrm{T}}-\mathrm{Yb}(\mathrm{b})$. The curves $1,1^{(+)}, 1^{(-)}$were obtained using aged textured silicon $\mathrm{Si}^{\mathrm{T}}{ }_{\mathrm{AG}}$, curves $2,2^{(+)}, 2^{(-)}-$after treating it in $\mathrm{HF}\left(\mathrm{Si}^{\mathrm{T}}{ }_{\mathrm{HF}}\right) .1,2-$ at $V_{0}=0 ; 1^{(+)}, 2^{(+)}$and $1^{(-)}, 2^{(-)}$, at $V_{0}= \pm$ 9.7 $\mathrm{V}$ on the $\mathrm{Si}^{\mathrm{T}}$ electrode, respectively.

If the Pt electrode is coupled with the $\mathrm{Si}^{\mathrm{T}}$ electrode playing the role of an anode, curves $2,2^{(+)}$, and $2^{(-)}$ (measured after etching the oxide film) possess some higher $A J(t)$ values as compared to the respective values for curves $1,1^{(+)}$, and $1^{(-)}$for the $\mathrm{Si}^{\mathrm{T}}{ }_{\mathrm{AG}}$ electrode with the oxide film. In the pair with the $\mathrm{Yb}$ electrode where the $\mathrm{Si}^{\mathrm{T}}$ electrode serves as cathode, curves 1 and $1^{(+)}$possess lower $A J(t)$ values as compared with those for curves 2, $2^{(+)}$curves only in the initial parts of the time dependences. At $t>20 \mathrm{~min}$, curve 1 is located above curve 2 , as well as curve $1^{(+)}$is above curve $2^{(+)}$at $t>6$ min. All these results indicate the changes in features of catalytic water decomposition both after deletion of the oxide film on the $\mathrm{Si}^{\mathrm{T}}$ electrode and after changing its role (anode or cathode).

The essential role of a relief and thermal oxidation of the $\mathrm{Al}$ electrode in the character of $A J(t)$ dependences for 
the pair Al-Pt is illustrated in Fig. 4. Curves 1' and 2' were obtained, respectively, on the plane $\mathrm{Al}^{\mathrm{P}}{ }_{\mathrm{AG}}$ and textured $\mathrm{Al}^{\mathrm{T}}{ }_{\mathrm{AG}}$ electrodes, both being aged in ambient air.

It is seen that the preliminary texturing of $\mathrm{Al}$ in an electrochemical bath with a chlorine salt solution considerably increases the catalytic activity of the $\mathrm{Al}$ electrode, which increases $A J(t)$. The latter value can be further increased in the course of thermal oxidation of $\mathrm{Al}^{\mathrm{P}}{ }_{\mathrm{AG}}$ and $\mathrm{Al}^{\mathrm{T}}{ }_{\mathrm{AG}}$ electrodes (see curves $1,1^{(+)}$, and $1^{(-)}$as well as $2,2^{(+)}$and $2^{(-)}$, respectively). The considerable distinction between curves $1^{(+)}$and $1^{(-)}$as compared with curves $2^{(+)}$and $2^{(-)}$indicates a considerable role of the electric field effects inherent to non-uniformities of the relief when decomposing molecules of water on the $\mathrm{Al}$ electrode.

Faster catalytic decomposition of water can be obtained not only by texturing the Al electrode but by its grinding, which is especially clear pronounced for the first $10 \mathrm{~min}$ of the decomposition. This is evident from the comparison of curves $2^{\prime}$ and $1_{\mathrm{Gr}}^{\prime}$ obtained, respectively, for the textured and grinded $\mathrm{Al}$ electrodes. Grinding the electrode made of nickel silicide $\mathrm{Ni}_{3} \mathrm{Si}$ increases the $A J(t)$ values by 1.5-2 times, when it is used as cathode coupled with the $\mathrm{Al}^{\mathrm{P}}$ AG anode. Grinding the Ti electrode (cathode) also increases twice the $A J(t)$ values obtained in the pair with the $\mathrm{Yb}$ electrode (anode).

The electrode made of a precious metal $(\mathrm{Pt})$ can be successfully substituted with the electrode from thermally oxidized chromium silicide $\mathrm{Cr}_{3} \mathrm{Si}_{\mathrm{TO}}$ that possesses $\varphi=$ $5.44 \mathrm{eV}$. In Fig. 5, we show the $A J(t)$ dependences for the pairs $\mathrm{Al}_{\mathrm{AG}}^{\mathrm{P}}-\mathrm{Cr}_{3} \mathrm{Si}_{\mathrm{TO}}$ (curves $1,1^{(+)}$, and $1^{(-)}$), as well as those for $\mathrm{Al}^{\mathrm{T}}{ }_{\mathrm{TO}}-\mathrm{Cr}_{3} \mathrm{Si}_{\mathrm{TO}}$ (curves $2,2^{(+)}$, and $2^{(-)}$). It can be

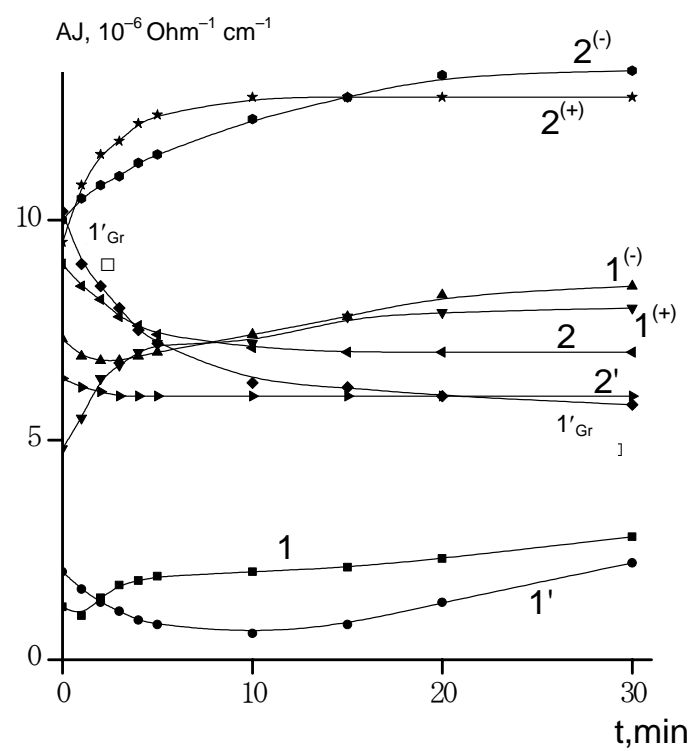

Fig. 4. $A J(t)$ dependences for the electrode pairs $\mathrm{Al}^{\mathrm{P}}{ }_{\mathrm{AG}}-\mathrm{Pt}$ (1'), $\mathrm{Al}^{\mathrm{T}}{ }_{\mathrm{AG}}-\mathrm{Pt}\left(2^{\prime}\right), \quad \mathrm{Al}^{\mathrm{P}}{ }_{\mathrm{TO}}-\mathrm{Pt}\left(1,1^{(+)}, 1^{(-)}\right), \mathrm{Al}^{\mathrm{T}}{ }_{\mathrm{TO}}-\mathrm{Pt}(2$, $\left.2^{(+)}, 2^{(-)}\right), \mathrm{Al}_{\mathrm{CB}}^{\mathrm{Gr}}-\mathrm{Pt}\left(1_{\mathrm{Gr}}^{\prime}\right)$. The curves $1^{\prime}, 2^{\prime}, 1,2,1_{\mathrm{Gr}}^{\prime}$ at $V_{0}=0$; the signs $(+)$ and $(-)$ correspond to $V_{0}= \pm 9.7 \mathrm{~V}$ on the $\mathrm{Al}$ electrode. seen that the $A J(t)$ values in Fig. 5 are considerably higher than those in Fig. 4, especially for the pair $\mathrm{Al}^{\mathrm{T}}{ }_{\mathrm{TO}}-\mathrm{Cr}_{3} \mathrm{Si}_{\mathrm{TO}}$. In our opinion, metal silicides are rather promising as cathodes for the more efficient current creation based on water decomposition.

The time dependence $A J(t)$ at $V=0$ obtained for the grinded $\mathrm{Ti}^{\mathrm{Gr}}$ electrode (cathode) coupled with the $\mathrm{Yb}$ electrode is shown in Fig. 6 with curve 0 . When the measurements last up to $2 \mathrm{~h}$, the $A J(t)$ values increase up to $21 \cdot 10^{-6} \mathrm{Ohm}^{-1} \mathrm{~cm}^{-1}, \Delta V_{k}$ being increased only from +1.14 to $+1.19 \mathrm{~V}(\operatorname{sign}(+)$ on the $\mathrm{Yb}$ electrode $)$.

In Fig. 6, curves 1, 2, 3, and 4 were obtained using the $\mathrm{Yb}$ electrode (anode) coupled with the $\mathrm{Ti}^{\mathrm{Gr}}$ electrode (cathode) covered via step-by-step deposition by the $\mathrm{Pd}$ impurity with the following concentrations: $2 \cdot 10^{16}$, $2 \cdot 10^{17}, 5 \cdot 10^{17}$, and $1 \cdot 10^{18} \mathrm{~cm}^{-2}$, respectively. In the course of deposition, Al served as anode. In this case, the $\varphi$ values determined relatively to the $\mathrm{Pd}$ electrode grew from 5.17 up to $5.39 \mathrm{eV}$. As seen from Fig. 6, at low concentrations $\left(2 \cdot\left(10^{16} \ldots 10^{17}\right) \mathrm{cm}^{-2}\right)$ of Pd deposited on the grinded $\mathrm{Ti}^{\mathrm{Gr}}$ electrode, the $A J(t)$ values are decreased (curves 1 and 2 as compared with curve 0 ). This means that, at the very beginning, $\mathrm{Pd}$ atoms neutralize catalytically active centers of a structural character, which arise after grinding.

A further growth of the concentration of deposited Pd impurity results in the creation of new catalytically active Pd centers which enhance the $A J(t)$ values (curves 3 and 4). Curve $4^{(-)}$obtained after applying the voltage $V_{0}=-9.7 \mathrm{~V}$ to the $\mathrm{Ti}^{\mathrm{Gr}}\left\langle\mathrm{Pd}_{4}\right\rangle$ electrode evidences a considerable growth of the catalytic activity inherent to the $\mathrm{Ti}^{\mathrm{Gr}}$ electrode doped with $\mathrm{Pd}$ in the presence of strong local electric fields on its surface.

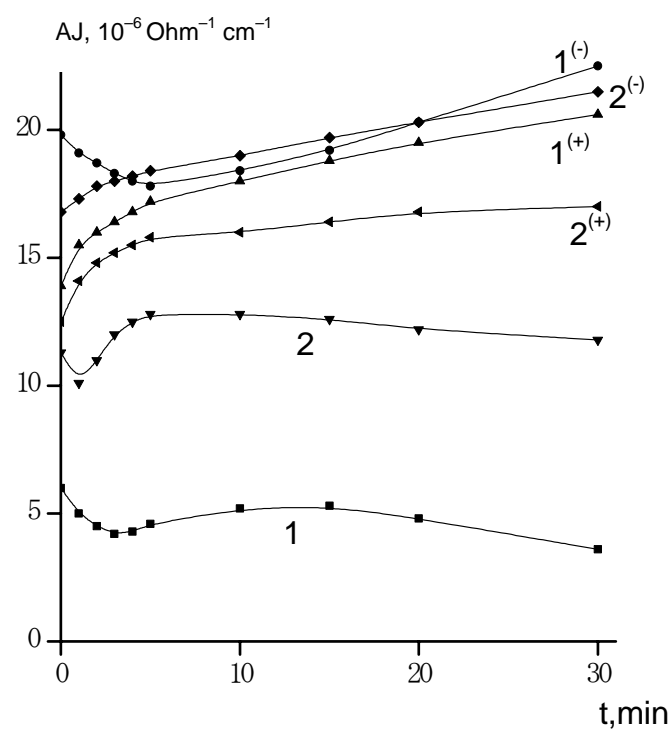

Fig. 5. $A J(t)$ dependences for the electrode pairs $\mathrm{Al}^{\mathrm{P}}{ }_{\mathrm{AG}}-\mathrm{Cr}_{3} \mathrm{Si}_{\mathrm{TO}}$ $\left(1,1^{(+)}, 1^{(-)}\right)$and $\mathrm{Al}^{\mathrm{T}}{ }_{\mathrm{TO}}-\mathrm{Cr}_{3} \mathrm{Si}_{\mathrm{TO}}\left(2,2^{(+)}, 2^{(-)}\right)$. The curves 1,2 were obtained at $V_{0}=0$; the signs $(+)$ and $(-)$ correspond to $V_{0}= \pm 9.7 \mathrm{~V}$ on the $\mathrm{Al}$ electrode. 


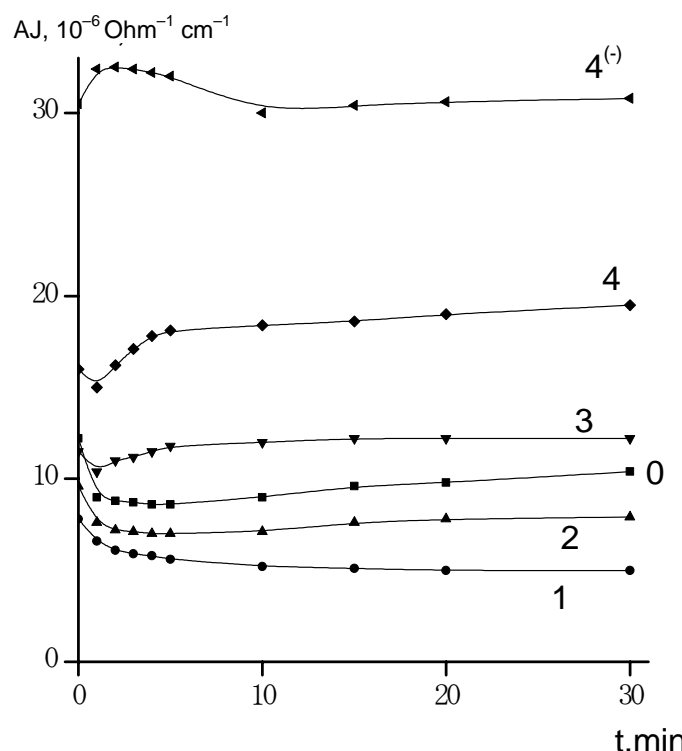

Fig. 6. $A J(t)$ dependences for the electrode pair $\mathrm{Ti}{ }^{\mathrm{Gr}}\langle\mathrm{Pd}\rangle-\mathrm{Yb}$. The curve 0 was obtained for the pair $\mathrm{Ti}^{\mathrm{Gr}}{ }_{\mathrm{CB}}-\mathrm{Yb}$ in absence of Pd impurity, curve $1-\operatorname{Pd}\left(2 \cdot 10^{16} \mathrm{~cm}^{-2}\right), 2-\operatorname{Pd}\left(2 \cdot 10^{17} \mathrm{~cm}^{-2}\right)$, $3-\operatorname{Pd}\left(5 \cdot 10^{17} \mathrm{~cm}^{-2}\right), 4-\mathrm{Pd}\left(1 \cdot 10^{18} \mathrm{~cm}^{-2}\right), 4^{(-)}-V_{0}=-9.7 \mathrm{~V}$ on the electrode $\mathrm{Ti}^{\mathrm{Gr}}\left\langle\mathrm{Pd}_{4}\right\rangle$.

The highest $A J(t)$ values were obtained when using the $\mathrm{Yb}$ electrode as anode and $\mathrm{Cr}_{3} \mathrm{Si}$ as cathode that was preliminarily covered electrolytically with the $\mathrm{Pd}$ impurity up to the concentration close to $1 \cdot 10^{18} \mathrm{~cm}^{-2}$. Fig. 7 illustrates the $A J(t)$ dependences for the pair $\mathrm{Yb}$ $\mathrm{Cr}_{3} \mathrm{Si}$ without doping $\mathrm{Cr}_{3} \mathrm{Si}$ with $\mathrm{Pd}$ (curve 0), when the concentration of the doping impurity is equal to $1.5 \cdot 10^{16} \mathrm{~cm}^{-2}$ (curve 1), as well as for the maximal concentration of the Pd impurity of $1 \cdot 10^{18} \mathrm{~cm}^{-2}$ (curves $2,2^{(+)}$, and $\left.2^{(-)}\right)$.

Moreover, in the catalytic water decomposition, an essential role is played by not only the $\mathrm{Cr}_{3} \mathrm{Si}\left\langle\mathrm{Pd}_{5}\right\rangle$ electrode but the $\mathrm{Yb}$ electrode as well, since the substitution of it with the $\mathrm{Al}_{\mathrm{AG}}^{\mathrm{P}}$ electrode results in considerably lower $A J(t)$ values (curves $3,3^{(+)}$, and $3^{(-)}$). The signs (+) and (-) marking curves in Fig. 7 mean the application of respective potentials, $V_{0}= \pm 9.7 \mathrm{~V}$, to the $\mathrm{Yb}$ or $\mathrm{Al}$ electrode.

When studying the current transfer provided by the pair $\mathrm{Yb}-\mathrm{Cr}_{3} \mathrm{Si}\left\langle\mathrm{Pd}_{5}\right\rangle$ for $2 \mathrm{~h}$ at $V_{0}=0$, we observed the growth of $A J(t)$ values up to $100 \cdot 10^{-6} \mathrm{Ohm}^{-1} \mathrm{~cm}^{-1}$. It is our highest value among those in works [1-3]. This means the creation of a current source with a current density close to $120 \mu \mathrm{A} \cdot \mathrm{cm}^{-2}$ and the potential difference between the electrodes $\Delta V_{k}=+1.8 \mathrm{~V}$, i.e., the power of this electrochemical system is close to $0.216 \mathrm{~mW}$ per $1 \mathrm{~cm}^{2}$ of the $\mathrm{Cr}_{3} \mathrm{Si}\left\langle\mathrm{Pd}_{5}\right\rangle$ electrode area. Note that the value $\Delta V_{k}=+1.8 \mathrm{~V}$ was the same both at $t=0$ and $t=2 \mathrm{~h}$.

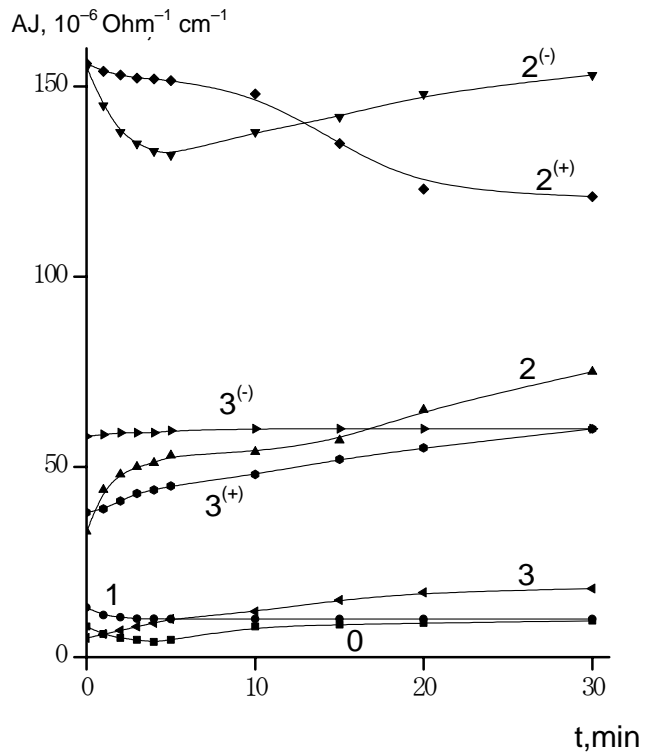

Fig.7. $A J(t)$ dependences for the electrode pairs $\mathrm{Yb}_{-}-\mathrm{Cr}_{3} \mathrm{Si}\langle\mathrm{Pd}\rangle$ (curves $0,1,2,2^{(+)}, 2^{(-)}$) and $\mathrm{Al}^{\mathrm{P}}{ }_{\mathrm{AG}}-\mathrm{Cr}_{3} \mathrm{Si}\left\langle\mathrm{Pd}_{5}\right\rangle$ (curves 3, $\left.3^{(+)}, 3^{(-)}\right)$. The curves $0,1,2,3$ were obtained at $V_{0}=0$; the signs $(+)$ and $(-)$ correspond to $V_{0}= \pm 9.7 \mathrm{~V}$ on the $\mathrm{Yb}$ and $\mathrm{Al}$ electrodes. The $\mathrm{Cr}_{3} \mathrm{Si}$ electrode was doped with $\mathrm{Pd}$ : $0(\mathrm{Pd}=0)$; $1\left(\mathrm{Pd}=1.5 \cdot 10^{16} \mathrm{~cm}^{-2}\right) ; 2,3\left(\mathrm{Pd}=1 \cdot 10^{18} \mathrm{~cm}^{-2}\right)$.

This means that the growth of $A J(t)$ values from $33 \cdot 10^{-6} \mathrm{Ohm}^{-1} \cdot \mathrm{cm}^{-1}(t=0)$ up to $100 \cdot 10^{-6} \mathrm{Ohm}^{-1} \mathrm{~cm}^{-1}$ $(t=2 \mathrm{~h})$ is realized due to the increase in the catalytic activity of electrodes (first of all, that of the $\mathrm{Cr}_{3} \mathrm{Si}\left\langle\mathrm{Pd}_{5}\right\rangle$ electrode, because the $\mathrm{Yb}$ electrode activity is constant in the system Yb-Pt (Fig. 1) at $t>20 \mathrm{~min}$ and does not practically depend on its oxidation degree). Curves $2^{(+)}$ and $2^{(-)}$corresponding to the maximum $A J(t)$ values confirm the essential influence of an electric field present on non-uniformities of doped $\mathrm{Pd}$ and on porous $\mathrm{Cr}_{3} \mathrm{Si}$ on the water decomposition.

In [2], we have already estimated the recovered energy as a result of the water decomposition in accord with the reaction $\mathrm{H}_{2} \mathrm{O} \leftrightarrow \mathrm{OH}+\mathrm{H}: 5.1 \mathrm{eV}$ per one $\mathrm{H}_{2} \mathrm{O}$ molecule [7]. However, in [2], we did not take into account the recovered energy (power) due to the current creation. Let us estimate a power gain under these conditions by taking into account both the current creation and the hydrogen output that can be also used for the energy yield.

The calculations made following the way described in [2] show that a current density of $120 \mu \mathrm{A} \cdot \mathrm{cm}^{-2}$ provides the release of approximately $6 \cdot 10^{12} \mathrm{OH}$ and $\mathrm{H}$ particles per one second. Their recombination in the course of the reaction $\mathrm{H}+\mathrm{OH} \rightarrow \mathrm{H}_{2} \mathrm{O}$ provides the power close to $4.8 \cdot 10^{-3} \mathrm{~mW}$, which is 45 times less than the value obtained due to the current $(0.216 \mathrm{~mW})$. Thus, the main source to recover energy in this process is the current, rather than the hydrogen output. 


\section{Conclusions}

1. We have investigated the time dependences for the current that arises between two electrodes with different electrochemical potentials when changing their catalytic activity as to the water decomposition by using the following physicochemical factors: natural and thermal oxidation of electrodes, changing the character of their relief (chemical structuring, grinding, polishing), and the electrolytic deposition of a catalytically active $\mathrm{Pd}$ impurity onto electrodes.

2. It was found that natural (as well as in the course of operation) oxidation of the $\mathrm{Yb}$ electrode most often used as anode due to the low electron work function does not practically influence the current after 20 min since abridging the $\mathrm{Yb}$-Pt electrodes.

3. Thermal oxidation $\left(450^{\circ} \mathrm{C}, 4 \mathrm{~h}\right.$ in dry $\left.\mathrm{O}_{2}\right)$ of electrodes $\left(\mathrm{Al}, \mathrm{Ti}, \mathrm{Ni}, \mathrm{Cr}_{3} \mathrm{Si}\right)$ increases the electron work function for them and, as a rule, enhances the current between them and a counterelectrode $(\mathrm{Yb}$, $\mathrm{Pt}, \mathrm{Al})$ both in the absence of an external voltage and at $V_{0}= \pm 9.7 \mathrm{~V}$.

4. The chemical structuring of the electrode (Al, Si) surface and the mechanical processing (grinding, polishing) of the electrodes ( $\mathrm{Al}, \mathrm{Ti}, \mathrm{Cr}_{3} \mathrm{Si}, \mathrm{Ni}_{3} \mathrm{Si}$, $\mathrm{Yb}, \mathrm{Si}$ ) change the electron work function for these electrodes and their catalytic activity as to the water decomposition due to changes in the structure of the electrode surface and a natural oxide film covering them.

5. As a rule, structuring the electrode surface results in the acceleration of the catalytic water decomposition both at $V_{0}=0$ and at $V_{0}= \pm 9.7 \mathrm{~V}$, which indicates an essential influence of the strong electric field arising at micro(nano)nonuniformities of the electrode structure on water decomposition.
6. The best current creation (at $V_{0}=0$ ) was observed in the case of the pair $\mathrm{Yb}-\mathrm{Cr}_{3} \mathrm{Si}\left\langle\mathrm{Pd}_{5}\right\rangle$, when the current density reaches $120 \mu \mathrm{A} \cdot \mathrm{cm}^{-2}$ at the voltage between the electrodes $\Delta V_{k}=1.8 \mathrm{~V}$. It has been calculated that the energy recovered due to the current creation is considerably higher (by tens of times) than that obtained with the use of reduced hydrogen.

\section{References}

1. V.E. Primachenko, B.M. Bulakh, S.I. Kirillova, V.A. Chernobai, E.F. Venger, Electronic properties of palladium doped porous silicon and decomposition of water without an external electric voltage on its basis // Ukr. Phys. J. 52(3), p. 236243 (2007).

2. V.E. Primachenko, I.V. Kud', S.I. Kirillova, V.A. Chernobai, Decomposition of water and application of electrode catalytic properties // Zhurnal Tekhnicheskoi Fiziki (2007) (be published) (in Russian).

3. V.E. Primachenko, A.A. Serba, V.A. Chernobai, E.F. Venger, Effect of oxidizing on water decomposition by catalytic active electrode on silicon based // Semiconductor Physics, Quantum Electronics and Optoelectronics 10(1), p.88 (2007).

4. Physical encyclopedia. Encyclopediya Publ., Moscow, 1988 (in Russian).

5. Short chemical encyclopedia. Encyclopediya Publ., Moscow, 1963 (in Russian).

6. S.I. Kirillova, V.E. Primachenko, A.A. Serba, L.P. Tarasenko, V.A. Chernobai, Temperature dependence of surface potential on textural silicon surface // Optoelektronika i Poluprovodnikovaya Tekhnika N 27, p. 29-35 (in Russian).

7. H.B. Gray, Electrons and Chemical Bonding. Benjamin, New York, 1964. 